\title{
Novos cultivos agrícolas hospedeiros de Phytophthora nicotianae
}

\author{
Marcos Vinícius Oliveira dos Santos ${ }^{1,2}$; Dilze Maria Argôlo Magalhães²; Ademilde de Oliveira Cerqueira ${ }^{2}$; Karina \\ Peres Gramacho²; Edna Dora Martins Newman Luz ${ }^{1,2}$.
}

${ }^{1}$ Programa de Pós-Graduação em Produção Vegetal, DCAA, Universidade Estadual de Santa Cruz, CEP $45662-000$ - Ilhéus, BA; ${ }^{2}$ Centro de Pesquisas do Cacau, CEPLAC, CEP 45600-970 - Ilhéus, BA.

Autor para correspondência: Marcos Vinícius Oliveira dos Santos (marcosvos@ymail.com)

Data de chegada: 21/11/2012. Aceito para publicação em: 30/03/2013.

No Sudeste da Bahia são escassas as pesquisas com Phytophthora spp. em propriedades rurais de pequeno porte, mas muitas espécies vegetais cultivadas nessas áreas são hospedeiras desse fungo.Por isso foram realizadas coletas de amostras de folhas, caules, raízes e solo (região da rizosfera) de diversos cultivos em propriedades rurais com esse perfil, nos municípios de Ituberá e Serra Grande, Bahia, em abril de 2009. Em laboratório procedeu-se ao isolamento das amostras em meio seletivo PARPH (Kannwischer, M.E.; Mitchell, D.J. Phytopathology 68: 1760-1765. 1978). As culturas de Phytophthora foram identificadas por critérios morfofisiológicos. Testes de compatibilidade sexual foram realizados pelo método de sanduíche (Luz et al. Glossário ilustrado de Phytophthora: técnicas especiais para o estudo de Oomicetos 204p. 2008). Em testes de patogenicidade feitos em câmara úmida, folhas destacadas dos respectivos hospedeiros de origem dos isolados de Phytophthora foram inoculadas com discos de micélio de culturas axênicas cultivadas em meio cenoura-ágar, com 10 repetições/isolado. Foram obtidos onze isolados de Phytophthora, do tipo compatível A2, provenientes da rizosfera de cultivos de agrião (Rorippa nasturtiumaquaticum (L.) Hayek) (1358), coentro (Coriandrum sativum L.) (1359), espinafre (Spinacea oleracea L.) (1360) no município de Ituberá e de tecidos vegetais de hortelã-miúda (Mentha x villosa Huds.) (1363, 1364, 1365 e 1366), da rizosfera de alecrim
(Rosmarinus officinalis L.) (1375, 1381 e 1390) e de jiló (1405) no município de Serra Grande. As colônias eram estreladas (1359, 1375 e 1390, Figura 1A) e petaloides do tipo crisântemo (demais isolados) com micélio aéreo variando de ralo (1365 e 1405) a ligeiramente cotonoso (demais isolados). As culturas formaram esporangióforos com ramificação irregular simples, esporângios predominantemente limoniformes (Figura 1B), 41,1 x $31 \mu \mathrm{m}$, não decíduos, com papila conspícua, 6,3 x 7,1 $\mu \mathrm{m}$. Observou-se a presença de clamidósporos, $26,3 \mu \mathrm{m}$, terminais e intercalares. Alguns isolados apresentaram intumescimento de hifas e todos cresceram a temperatura de $35{ }^{\circ} \mathrm{C}$. Todos os isolados foram patogênicos aos cultivos de origem (exemplo, Figura 1C) e reisolados posteriormente, sendo classificados como Phytophthora nicotianae Breda de Haan (Waterhouse, G.M. Key to the species of Phytophthora de Bary 22p. 1963). Entre os cultivos, mencionados, somente o alecrim e o coentro já são hospedeiros de $P$. nicotianae, porém, este é o primeiro relato de $P$. nicotianae em jiló, espinafre, agrião e em hortelã-miúda, sendo estes novos hospedeiros desta espécie. Recentemente, diagnosticaram-se isolados de $P$. nicotianae dos tipos compatíveis A1 e A2 em cultivos na região Sudeste da Bahia (Santos et al. New Disease Reports 24: 28. 2011; Santos et al. Summa Phytopathologica 37: 153. 2011), podendo assim, favorecer o surgimento de recombinantes com maiores características de adaptabilidade.
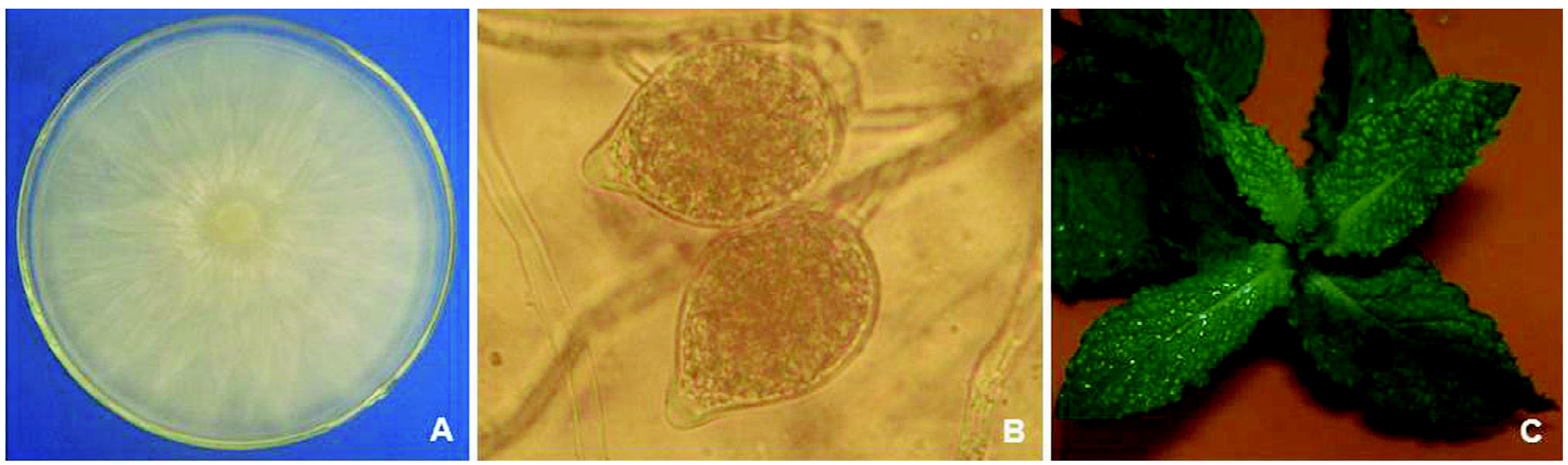

Figura 1. Colônia do isolado (1360) de Phytophthora nicotianae em meio de cultura cenoura-ágar (A). Esporângios de P. nicotianae, 1366 (B). Lesão causada, em testes in vitro, pelo isolado 1366 em folhas de hortelã-miúda (C). 